\title{
El ciclo de las costureritas: trabajo, género, política y modos de leer entre 1920 y 1930
}

\author{
Florencia Angilletta \\ Universidad de Buenos Aires - Consejo Nacional de Investigaciones Científicas y Técnicas \\ florenciangilletta@gmail.com \\ ORCID: 0000-0002-2156-9189
}

Title: The Cycle of Seamstresses: Work, Gender, Politics and Ways of Reading between 1920 and 1930

Resumen: Este artículo propone el dispositivo crítico "ciclo de las costureritas" como un modo de leer el trabajo "desde el género". En tanto articulación entre literatura y vida, opera ante la "división sexual del trabajo", productora de la escisión de esferas -pública/privada-y trabajos - productivo/reproductivo- según sexo-género. Fundado por la poesía "La costurerita que dio aquel mal paso", de Evaristo Carriego (1913), este ciclo desborda hacia otras décadas, pero en los 20 y 30 adquiere inflexiones en la literatura, letras de tango, fotografias y películas que producen desvios, alianzas e interrogaciones sobre los desplazamientos de las mujeres por lo público.

Palabras clave: costureritas - trabajo - modos de leer - género

Abstract: This article proposes the critical device "cycle of seamstresses" as a way of reading the work from the perspective of gender studies. Articulating literature and life, it operates before the "sexual division of labor", producing the division of spheres -public/private- and work -productive/reproductive- according to sex-gender. Founded in Evaristo Carriego's poem "La costurerita que dio aquel

DOI: https://doi.org/10.46688/ahmoi.n20.345

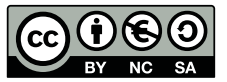

Obra bajo licencia Creative Commons 4.0 International (Atribución - NoComercial - Compartirlgual) 
mal paso" (1913), this cycle overflows into other decades, but in the twenties and thirties it acquires inflections in literature, tango lyrics, photographs and movies that produce deviations, alliances and interrogations about the displacement of women in the public sphere.

Keywords: seamstresses - work - ways of reading - gender

Recepción: 3 de diciembre de 2021. Aceptación: 22 de febrero de 2022.

$* * *$

En este artículo el "ciclo de las costureritas" es propuesto como un dispositivo crítico que tracciona "modos de leer" (Ludmer, 1985) el trabajo "desde el género" (Molloy, 2002) durante las primeras décadas del siglo XX. Fundado entre literatura y vida a partir del poema "La costurerita que dio aquel mal paso", de Evaristo Carriego, de 1913, este ciclo adquiere formas neurálgicas durante la época que integran las décadas del 20 y del 30 en algunas zonas de la literatura, las letras de tango, la prensa, la fotografia y el cine. La idea-fuerza es que, si bien no todo trabajo femenino en las primeras décadas del siglo XX puede reducirse a la costura, la costura puede leerse en tanto fábrica de producción de las tensiones sobre el trabajo de las mujeres, en especial, sobre circulación, respetabilidad y producción. ${ }^{1}$ A la vez, la lectura espacial intenta no esencializar el análisis del trabajo -como un rastreo de trabajadoras o de personajes-, ni limitarlo a su carácter economicista-como un repertorio de retrato social-.

La propuesta de este dispositivo crítico opera como una tramitación de los desplazamientos de las mujeres por lo público ante las luces del centro -ocio-, el trabajo asalariado y el consumo, en tanto modos de torsionar o poner en cuestión la domesticidad, así como otras dimensiones de la llamada "modernización". También fricciona las maneras de leer las hipótesis de las esferas, al mostrar zonas de reimaginación entre la agencia y la sujeción desde los géneros que intervienen ante distinciones organizadoras de la época, como Boedo y Florida, político y personal, trabajo y lucha, arte y compromiso. ${ }^{2}$

El ciclo de las costureritas en los 20 y 30 incluye letras de tango, Tangos de Enrique González Tuñón, la intervención de Jorge Luis Borges sobre Carriego, las reescrituras en los textos de María Luisa Carnelli y la película Mujeres que trabajan, de Manuel Romero. Los siguientes

1. Aunque no se entrecomille "mujeres", su utilización busca incluir los cuestionamientos sobre las tensiones entre la nominación y la subjetividad política de los feminismos en las distintas épocas.

2. Sobre las tensiones entre "forma" y "contenido" ver, entre otros, Alle (2015) y Vitagliano (2012). 
apartados ordenan la forma de este ciclo organizado por los debates entre estética y política. A la vez, incorporan menciones que yuxtaponen el análisis con otras textualidades y sus mediaciones. Estos modos de leer textos transitados por la crítica literaria junto con otros menos conocidos construyen un archivo de materiales al que interrogar sobre las formas del trabajo en las primeras décadas del siglo XX en la Argentina.

La lectura propuesta no es económica o social -a la manera de un impresionismo de escenas laborales-, sino política, pero que a la vez no implica la politización compulsiva, sino las producciones etnográficas, situadas y contradictorias, de subjetividades y ciudadanías, que desde los textos torsionan las hipótesis de la "modernización" en tanto escisión o segmentación. No se trata de dar por sentado las construcciones de identidades cristalizadas -lo que las trabajadoras "son"-, ni de buscar en la literatura un correlato o correspondencia de esas representaciones -lo que las trabajadoras "representan"-. Aquí se anudan dos conflictos centrales para pensar el mundo del trabajo y la política: el problema de la identidad y el de la representación. Las escrituras aquí reunidas conforman una apuesta para leer la historia de las mujeres en los circuitos laborales. Cruzar el mundo del trabajo y el de las mujeres habilita, además, una pregunta central: leer dónde está el trabajo, qué parte lo produce, dónde está su valor, cómo se lo negocia o salariza, qué mezcla, cómo se construye la clase, cuándo sucede la movilidad. En definitiva, una discusión en la cual se enlazan la literatura y la política.

En este artículo, "ciudad" es la forma de nombrar una organización atravesada por las hipótesis de la "modernización", mientras que "arquitectura" enfatiza los modos de subjetivación en los que esa ciudad es vivida por las mujeres. Desde la literatura, la arquitectura hace de la ciudad una tecnología de lo viviente. ${ }^{3}$ Durante la "modernización", el Estado-nación, las revoluciones burguesas, las ciudades, las formas de producción económica capitalista anudan una distinción entre un espacio productivo, asalariado y reconocido, en el que la mayoria de los asignados son los varones; de un espacio reproductivo, no asalariado y no reconocido, en el que la mayoría de las asignadas son las mujeres. Esta distinción se vincula con una de las operaciones básicas de la modernidad, que es la división por esferas: el espacio privado, el público y el estatal, como señala Habermas (1981). Los feminismos leen esta distinción como "división sexual del trabajo" (Scott, 1993) al mostrar la jerarquización y las relaciones de poder puestas en juego, así como sus modos de intervención y fundación de nuevos itinerarios.

En la primera mitad del siglo XX, el trabajo puede ser abordado como

3. A partir de la hipótesis de Preciado (2010), "arquitectura" es el modo de leer la tramitación y producción subjetiva que las mujeres hacen de la ciudad. 
un modo de leer la conexión entre economía y sociedad. Las alternativas más habituales para las mujeres pasan por ser "costureras", es decir, mujeres que realizan tareas domésticas, o que a lo sumo llevan a cabo labores pagas en sus casas -"coser para afuera"-; o "maestras normales", que se incorporan a la vida pública en tanto extensión del rol maternal, como estudia Nari (2004). De este modo, el trabajo de las costureras es realizado mayormente dentro del hogar, aunque requiere circulación para su encargo y entrega; estos desplazamientos dinamizan la relación público-privado al punto tal que la trayectoria de quienes inician una travesía es nombrada a partir de esta profesión. ${ }^{4}$

El ciclo de las costureritas aglutina a aquellas que desobedecen el mandato de ser costureras. En efecto, cierta narrativa masculina las nombra con el diminutivo y este gesto, hasta un tanto despectivo, muestra en el mismo lenguaje la diferencia respecto de quienes sí cumplen el mandato de domesticidad, como las costureras o maestras. A través de este dispositivo crítico, pueden ser leídos los años 20 y 30 en tanto interrogación desde los géneros hacia las tramas y moldes de una época que no cesa de afectar al presente, con sus tensiones en torno a una "literatura de izquierda", la arquitectura urbana, la sociedad de masas, la progresiva conquista de derechos, las luchas anarquistas y socialistas y el golpe de Estado con su ciclo conservador.

"La costurerita que dio aquel mal paso", poema fundacional de este ciclo, inaugura la serie de la trayectoria de las jóvenes que salen del barrio -o de los pueblos- y migran al centro. ${ }^{5}$ Es escrito por Evaristo Carriego, "fundador" del barrio según lo interpelan las apropiaciones posteriores, como la de Borges. ${ }^{6}$ Esta textualidad permea la imaginación en torno a la posibilidad de la "caída" y los cruces entre trabajadoras y "putas", signados por la amenaza que orbita sobre las mujeres que salen de sus casas: costureras, vendedoras, obreras, secretarias, oficinistas, actrices, cantantes de tango, militantes políticas.

4. Sobre las mujeres que trabajan en las primeras décadas del siglo $\mathrm{XX}$, ver Lobato (2007) y Queirolo (2020), entre otras.

5. "La costurerita que dio aquel mal paso... / -y lo peor de todo, sin necesidad- / con el sinvergüenza que no la hizo caso / después... -según dicen en la vecindad- / se fue hace dos días. Ya no era posible / fingir por más tiempo. Daba compasión / verla aguantar esa maldad insufrible / de las compañeras, ¡tan sin corazón! / Aunque a nada llevan las conversaciones, / en el barrio corren mil suposiciones / y hasta en algo grave se llega a creer. / ¡Qué cara tenía la costurerita, / qué ojos más extraños, esa tardecita / que dejó la casa para no volver!...” (Carriego, [1913] 1999: 143).

6. Carriego (1883-1912) nace en Paraná, Entre Ríos, y vive en Palermo, Buenos Aires, en los primeros años del siglo XX. Publica Las misas herejes (1908) y, de forma póstuma, La canción del barrio (1913). Sobre Carriego, ver Monteleone (2006) y Freidemberg (1996), entre otros/as. 
Con estos modos de leer, se tensiona la dicotomización típica de la primera mitad del siglo XX entre ámbito público y privado. Desde la literatura, más que pensar en una "salida", se proponen desplazamientos, así como flujos entre las esferas. Leer-desde los feminismos- como trabajo el cuidado de la vida enlaza la productividad en la domesticidad con el capitalismo, y las conquistas ciudadanas con otras prácticas de esa incipiente sociedad de masas, como la prensa, el paseo, el ocio, el consumo. ${ }^{7}$ En su conjunto, la lectura sobre el trabajo permite explorar los encuentros entre literatura, cultura, política y Estado como modos de producción de ciudadanía, así como otras instancias que contradicen, alteran y reformulan la producción de subjetividad.

"La costurerita que dio aquel mal paso" construye tres dispositivos críticos: el de la "costurerita", el del "mal paso" y el del demostrativo "aquel", que funciona como vinculación. El de la "costurerita" se tensiona en oposición con la "costurera" y los mandatos domésticos. Esa domesticidad, así como sus relaciones con las escenas de trabajo y producción, operan en una línea producida desde el cuadro "Sin pan y sin trabajo" (1894), de Ernesto De la Cárcova. ${ }^{8}$ A diferencia de obras futuras como "Manifestación" o "Desocupados", de Antonio Berni-ambas de 1934-, el cuadro de De la Cárcova resalta por la incorporación visionaria de una mujer y un bebé; en él, las mujeres y los niños forman parte ineludible de la escena del trabajo o de la desocupación. Series siguientes disocian estas escenas: la de la manifestación o lucha respecto de la doméstica. Si bien imágenes posteriores muestran la colectivización de la lucha que en el cuadro aparece contenida dentro de lo familiar, este tránsito hacia lo público pierde la conexión inaugural y pionera que el cuadro mantiene entre la escena de producción y la de reproducción que el trabajo pone en contacto. El cuadro articula lo que una fase de la "modernización"

7. Distintas investigaciones feministas destacan que en la Revolución francesa y la rusa la intervención de las mujeres es decisiva, en especial, a partir de las luchas que desencadena el aumento del pan. De hecho, "pan y rosas", consigna histórica de las huelguistas de principios del siglo XX, sintetiza la imagen de esa lucha por la vida posible. Con vidas y luchas de entre siglos -entre el XIX y el XX-, Alexandra Kollontai, Rosa Luxemburgo y Clara Zetkin irrumpen las coagulaciones entre izquierdas y feminismos. En la Argentina son muchas las mujeres que traccionan de modo pionero ente las izquierdas y los feminismos. Para producir el capital o combatir esa forma de distribución, alguien tiene que cuidar a los/as hijos/as y hacer la comida. Los feminismos se preguntan por qué ese alguien siempre son las mismas personas.

8. Como señala Malosetti Costa (2001), constituye el primer cuadro (obrero) con crítica social en el arte argentino; es pintado al final del viaje de estudios de De la Cárcova en Turín y Roma, donde toma contacto con el naturalismo como modo de afrontar el conflicto social urbano. Esta mixtura entre la experiencia europea y la producción de una imagen, luego icónica de la pintura nacional, es organizadora de esas zonas de contacto del "ojo estrábico", que impulsa la cultura argentina desde el siglo XIX. 
en cierta medida escinde: la pobreza como afectación de la vida y las condiciones materiales de trabajo como aquello que vincula la mesa familiar con la vida laboral.

En el poema de Carriego, el diminutivo "costurerita" funciona porque presupone a la costurera, quien, como en el cuadro, cuida al bebé en brazos y baja la vista hacia el espacio de la domesticidad, mientras que la "costurerita" toma la costura como elemento doméstico fronterizo y hace de esta posibilidad una travesía, en la que se enclava la fascinación y el rechazo de la época. El dispositivo crítico del "mal paso" es una forma de desplazamiento del ámbito público que fricciona los mandatos domésticos y habilita -a la vez que sospecha- la circulación por el centro, los márgenes, las periferias.

El demostrativo "aquel", con su marcación deíctica, señaliza que el "mal paso" es una textualidad continua entre literatura y vida, que la lectura de la época puede reponer. En ese "aquel" se organiza la productividad del ciclo de las costureritas: no es que "La costurerita que dio aquel mal paso" invente ni copie, sino que funda desde la literatura una textualidad que organiza la vida, a la vez que produce formas que la ponen en circulación. Este poema es publicado en el libro póstumo La canción del barrio en 1913, un año después de la sanción de la Ley Sáenz Peña, cuando la ciudadanía muestra un filón múltiple de institucionalización y de lucha: las multitudes empiezan a tener un primer contacto con el Estado a partir de las transformaciones desde el radicalismo y el yrigoyenismo, y crece la militancia anarquista, socialista y sufragista.

El significante "caída" está presente en distintas investigaciones sobre la época (Barrancos, 1999; Lobato, 2007; Nari, 2004). Según Lobato, los trabajos femeninos escenifican la tensión entre deshonra y virtud, a la vez que contribuyen a escenificar mitos "en la medida en que las imágenes se multiplican hasta convertirse en un punto natural" (2007: 298). En sus distintas inflexiones, este mito orbita en la cultura de esos años. Armus sostiene que la poesía de Carriego, "La costurerita que dio aquel mal paso", "se ha cristalizado en la memoria colectiva de la ciudad" (2002: 80). En ella se condensa la trayectoria de la joven que, tentada por las luces y las promesas del centro, abandona la vida del barrio, pero termina, sin suspenso, en la "caída" que la conduce a la desdicha y la enfermedad. ${ }^{9}$

9. Trabajos previos sobre las costureritas pueden rastrearse en Armus (2002), Diz (2012), Mitidieri (2021), Queirolo (2020), Saitta (2006), Tossounian (2021). Si bien distintas investigaciones exploran materiales sobre costureritas, la proposición del ciclo de las costureritas es inaugural como una trama de lectura del siglo XX. Las décadas del 20 y del 30, así como la época que puede leerse a través de ellas, resultan fundamentales de esta articulación, que tiene cierta culminación durante el peronismo y, a la vez, continúa hasta el presente, como se señala al final del artículo. 
En el poema no hay nombre propio, es justamente la profesión -costurera- y el diminutivo - costurerita- los que producen los modos de subjetivación: una nueva dinámica laboral, no exenta de infantilización. La enunciación de esta construcción infantil es la forma a través de la cual se tramitan los posibles riesgos que conlleva el viaje al centro por seguir al "sinvergüenza que no la hizo caso" (Carriego, 1999, p. 143). Este rasgo infantil e ingenuo se enfatiza en el poema "Caperucita roja que se nos fue" al comparar a la costurerita con la protagonista de la fábula infantil que equivoca su circulación -y por eso se encuentra con el lobo-. ${ }^{10}$ Después el poema concluye: "Mi madre disimula, pero a escondidas llora / con el supersticioso temor de verte lejos... / Caperucita roja, ¿dónde estarás ahora?” (p. 144). No se responde a esta pregunta espacial; estos poemarios inician el ciclo de la costurerita, pero solo enuncian desde el trayecto del barrio y el lamento por la partida. Son las escrituras de los años 20 y 30 las que indagan otras trayectorias del espacio y describen, sí, la dinámica del centro y de los márgenes, la arquitectura de los desplazamientos.

\section{Canta el tango como ninguna}

Según Armus, en los años 20 y 30 el legado de Carriego es retomado por las letras de tango, la literatura y el cine, que construyen la "leyenda romántica del otro mundo"; es decir, la vida de las "milonguitas" en el cabaret y en el centro. ${ }^{11}$ Mediante la "conformación de un lenguaje laboral generizado, basado en la contradicción moral/trabajo/espacio público" (Lobato, 2007, p. 330), se activa un imaginario según el cual

10. La famosa historia de Caperucita Roja forma parte de los cuentos tradicionales compilados por Charles Perrault en el siglo XVII. Esta ficción, entre otras, condensa una expectativa compartida: el temor a que las mujeres fértiles -ya atravesadas por la sangre-circulen por el espacio común -el bosque- sin seguir las recomendaciones de las madres y puedan ser devoradas por un lobo -ícono máximo de la "temeridad" masculina-. La interpretación, aunque ciertamente obvia, resulta efectiva por lo extrema: las violaciones no son, como señala Despentes (2007), una experiencia lateral que les ocurre a unas pocas mujeres, sino que constituyen el centro de los temores de la vida social.

11. Tal como documenta Salomone (2006), "Milonguita" es el título de un tango compuesto en 1920 con letra de Linning y música de Delfino, estrenado en 1920 en la representación del sainete Delikatessen House, y que ese mismo año Carlos Gardel y Raquel Meller graban en disco. Según Salomone (2006: 244), "su texto se articula desde la voz de un narrador que interpela a Milonguita, una mujer de cabaret, recordándole su antigua identidad cuando era la Estercita inocente que vivía en el barrio". 
las costureritas, las milonguitas y las trabajadoras que se alejan de la "ideología de la domesticidad" (Scott, 1993) caen en la prostitución. ${ }^{12}$

"Milonguita" (1920) es fundacional sobre esta inflexión de la costurerita con sus pasos por la vida del centro y el cabaret. Muchas letras de tango han condensado este imaginario: "Flor de fango" (1917, letra de José María Contursi), "Margot" (1921, letra de Celedonio Flores), "Milonguera" (1925, letra de José María Aguilar), "Pompas de jabón" (1925, letra de Enrique Cadícamo), "Mano cruel" (1928, letra de Armando Tagini), "Muñeca brava" (1929, letra de Enrique Cadícamo) y "Atenti, pebeta" (1929, letra de Celedonio Flores). ${ }^{13}$

En "Flor de fango" el punto de vista de la enunciación es de quien conoce -"te manyo de hace rato"- y puede reponer la totalidad de la "tragedia" acontecida: describir los elementos de la vida del centro -"las alhajas, los vestidos a la moda y las farras de champán"-, las compañías como el boticario y el comisario, e incluso señalar el momento en que "empezó tu decadencia". En "Pompas de jabón", la operación también es de quien conoce y nombra como "pebeta de mi barrio", pero a diferencia del tango anterior aún la "caída" no ha acontecido, solo se describen las actuales prácticas: "andás paseando en auto con un bacán, que te has cortado el pelo como se usa y que te lo has teñido color champán". La interpelación busca advertir sobre el futuro -que la enunciación considera inmodificable- y abogar por un cambio de vida. Por el contrario, en "Atenti, pebeta", la escritura se construye desde la prevención y la advertencia: "cuando vengas para el centro, caminá junando el suelo, arrastrando los fanguyos y arrimada a la pared".

Los cruces entre tango y poesia se plasman hasta en la intertextualidad con el mismo nombre de Carriego: "parecés un verso del loco Carriego" ("Viejo ciego", 1925, letra de Homero Manzi) o "¿acaso tu pena es la que Carriego, rimando cuartetas, a todos contó?" (“Cabeza de novia”,

12. Estas textualidades, en especial las de la década del 20, pueden ponerse en serie con la proliferación de las escrituras del ciclo de las costureritas en la novela semanal, como las de Josué Quesada "La costurerita que dio aquel mal paso" (1919) y "La vendedora de Harrod's" (1919).

13. Aguilar (1891-1951), Cadícamo (1900-1999), Contursi (1911-1972), Flores (18961947) y Tagini (1906-1962) son algunos de los letristas de tango de las primeras décadas del siglo XX, cuyas escrituras exploran, aun con sus matices, formas que transitan entre el arrabal, el tango canción y la nostalgia del suburbio ante la nueva arquitectura. Las letras seleccionadas tramitan las tensiones que esta música produce respecto de los desplazamientos de las mujeres por lo público. Si bien la mayoría de los compositores son varones, varias mujeres forman parte de la producción tanguera, como las aquí nombradas María Luisa Carnelli y Azucena Maizani. Todas las letras de tango son tomadas de Romano (2007). Sobre los vínculos entre tango y política, ver Varela (2016). 
1929, letra de Cadícamo). Los mestizajes entre tango y poesía habilitan que en el cancionero convivan elementos del lunfardo, como "mishé", "camba", "junando" o "fanguyos", junto a metáforas como "derrochás tus abriles" o metonimias del tipo "a esos sobretodo con catorce ojales no les des bolilla".

En "Flor de fango", "Pompas de jabón" y "Atenti, pebeta" persiste la escisión espacial entre barrio y centro, complejizada con la dimensión temporal. Hay tangos que, a la manera de un narrador omnisciente, relatan el comienzo, desarrollo y fin "trágico" de la peripecia; algunos interpelan sobre el fatal destino de la vida "licenciosa", y otros advierten a las muchachas sobre los peligros del centro. Sin embargo, aun en sus diferencias, construyen narrativas "trágicas" -el destino está contenido en el comienzo- que homogeneizan los modos de subjetivación -"como tantas flores de fango, irás por esas calles a mendigar"-. Se suprimen las historias, o al menos, "la trayectoria de la costurerita no tiene suspenso" (Armus, 2002, p. 239).

\section{Todos los márgenes el margen}

Las glosas de Enrique González Tuñón en los años 20 retoman las trayectorias de las milonguitas, en una inflexión que incorpora la conflictividad de un nombre propio, una historia y un motivo. Si antes las costureritas son "flores de fango" en las que se tramita la diferencia en la igualdad -la historia de todas es la historia de una-, las reescrituras posteriores tramitan la igualdad en la diferencia -la historia de una es la historia de ella-. En Tangos (1926), glosas de Tuñón para el diario Crítica, se construyen varias historias a partir del cancionero y "apun$\mathrm{ta}[\mathrm{n}]$ a la complejización del conflicto [con] procedimientos tales como metáforas y personificaciones que resignifican las identidades sexuales" (Diz, 2010, p. 3). En la arquitectura de los espacios, Tangos amplía la ciudad con la incorporación del arrabal y los bajos fondos, y reformula la tensión entre el barrio y el centro con la inclusión de un nuevo espacio estético: los márgenes.

La trayectoria de la milonguita atraviesa las glosas "Bichitos de luz", "Coralito", "Rulitos" y "Callecita de mi barrio", aunque con construcciones disímiles. En "Bichitos de luz", el escenario de la acción es un bar de los bajos fondos y la protagonista es "La romántica", una tísica que "emboba" a todos los parroquianos (González Tuñón, 2003, p. 41). Su final no es "trágico": sale del bar con el menos pensado, el hombre de la pata de palo. "Coralito" relata la historia de quien deja el suburbio, triunfa en el centro y muere finalmente por una sobredosis de cocaina. "Rulitos" también recrea la trayectoria de quien abandona el barrio e incluso se niega a volver cuando el novio de antaño la busca; ella también 
muere por una sobredosis de cocaina. "Callecita de mi barrio" narra la historia de Regina; su ingreso en el mundo de la noche es una forma de ganarse la vida ante la pobreza de sus condiciones materiales, y su final se liga a cierta evocación nostálgica del pasado.

Tangos recupera el imaginario de "La costurerita que dio aquel mal paso" y el de las milonguitas de las letras de tango en construcciones como "dio el mal paso por necesidad. Su alma milonguera había sido modelada con el barro del arroyo Maldonado" (p. 120); "otra vez las luces del centro malograron la inocencia del suburbio" (p. 142); "un mal paso empujó a Regina hacia la calle Maipú" (p. 152). Sin embargo, en la arquitectura de este espacio de los márgenes no todo es conmiseración: es recurrente la alegría y por eso las muchachas están "dilapidando sonrisas" (p. 39). Incluso la trayectoria al centro permite el disfrute, aunque limitado: "conquistó el centro y se bañó en el bullicio de sus luces" (p. 122).

Estas milonguitas ya no son las ingenuas "caperucitas"; pueden tomar decisiones sobre sus formas de vida. "La romántica" dice: "Soy de otra pasta y nunca lograré querer, porque hice del olvido una profesión de fe" (p. 42). Coralito afirma: "Ya no podría vivir la vida mezquina de antes... levantarme con el sol y salir a despertar las calles camino del trabajo" (p. 145).

En "Callecita de mi barrio", se radicaliza la construcción de la milonguita sin escindirla de las condiciones materiales de posibilidad: "Entre entregar cacho a cacho su juventud a la fábrica de bolsas de arpillera para terminar sus dias con la resignación de una obrera jubilable y disfrutar de ella bordeando el abismo, prefirió esto último. Hizo bien" (p. 152). En estas coordenadas, "la prostitución es más digna que el trabajo en fábricas. El margen, entonces, no es un lugar sino un punto de vista desde el cual González Tuñón crítica la sociedad actual” (Diz, 2010, p. 6). Tangos no romantiza los márgenes, sino que muestra los modos -incluso por momentos en común- en el que las costureritas desafian los mandatos de domesticidad y construyen agencias donde el poema fundacional de Carriego insinuaba prácticas de sujeción. ${ }^{14}$

14. Aunque ciertas textualidades de escritoras resultan cercanas al espacio de Boedo, de modo sintomático no son leídas por los escritores boedistas como parte de ese grupo. "La" escritora boedista es Clara Beter, que después se descubre una invención de César Tiempo. Versos de una... son poemas cuya autoría es una ficción política, la de una prostituta ucraniana, que en 1926 reescribe el ciclo de las costureritas: "Me entrego a todos, mas no soy de nadie; / para ganarme el pan vendo mi cuerpo / ¿Qué he de vender para guardar intactos / mi corazón, mis penas y mis sueños?" ("Quicio", Beter, 1926, p. 15). La operación de Clara Beter constela con la escritura de Nicolás Olivari, cuya originalidad es releer el ciclo con humor y extremar la pregunta espacial: "Pobre la costurerita que dio el paso malvado...! / Pobre si no lo daba, que 


\section{La costura, fábrica de nación}

Aquí se proponen cruces entre la lectura de la tecnología a través de las instituciones y los medios de comunicación, así como a través de las transformaciones domésticas. Los cambios de los electrodomésticos ordenan las mediaciones tecnológicas (que suelen ser pensadas a través de los saltos técnicos de las telecomunicaciones -con el ejemplo paradigmático de la radio en las primeras décadas del siglo XX-), pero la lectura de las formas de vida precisa yuxtaponer los cambios en los medios de tecnificación de lo viviente. Uno de estos elementos es la máquina de coser.

Distintas publicidades de la Singer internacional cristalizan la tensión entre costurera y costurerita. ${ }^{15}$ Para publicitar sus máquinas, Singer recurre a la filiación intergeneracional entre madre e hija alrededor de una escena doméstica: madre e hija, continuidad de la costurera. De este modo, se refuerza la hipótesis de la costurerita como aquella que desafia este mandato espacial (hogar) y laboral (costura), y así dinamiza una práctica de subjetivación diferencial. La costura opera como un aprendizaje doméstico entre madre e hija y, a la vez, resulta el espacio donde puede producirse un desvio; lugar bifronte que modula la domesticidad y a la vez habilita las diferencias. La revolución industrial no existe sin una revolución textil: la relación entre las multitudes y la costura se entrama a partir de la moda. Así, lo desnudo y lo vestido orbitan como modos de lectura sobre los cuerpos, y los géneros tramitan parte de estas periferias a través de los cambios que acontecen en las prendas (Saulquin, 2006). La moda resulta un dispositivo de tránsito entre mercado, modos de subjetivación, cultura del consumo y cultura política; leída como texto, ofrece saltos en las formas de vida de la primera mitad del siglo XX para las mujeres, así como prácticas de reimaginación de lo común.

En la Argentina del siglo XX, la construcción entre costura, mujeres y escritura adquiere una inflexión específica con la costurera y la cos-

aun estaría / sino tísica del todo, poco le faltaría. / Ríete de los sermones de las solteras viejas, / en la vida muchacha, no sirven esas consejas / porque... piensa!... si te hubieras quedado...!" (Olivari, 2008, "La costurerita que dio aquel mal paso": 64). Estas reescrituras, a su vez, colisionan con los desplazamientos del tango "Se va la vida" (1929) de María Luisa Carnelli, interpretado por Azucena Maizani.

15. En 1851, Merrit Singer funda, junto al abogado Clark, la Singer Corporation, empresa que patenta la máquina. Si bien el dispositivo ya existía, logra que la aguja se mantenga en movimiento vertical y evita que los hilos se enreden, lo cual representa un salto técnico. A partir de entonces el modelo se expande. La patente es "el motor de coser". Al final de la Primera Guerra Mundial, son tan populares que están en uno de cada cinco hogares en el mundo. 
turerita. La domesticidad es un territorio de intervención, un espacio al cual tecnificar, eficientizar, dotar de sentidos singulares vinculados con una posición distinta de las mujeres, no solo fuera de sus casas sino dentro de ellas. Diversos manuales, bibliografias y prensa periódica producen esta tarea vinculada con el moldeamiento de la domesticidad (Nari, 2004, entre otras), leído por Armstrong (1987) como espacio de poder en su análisis de la novela inglesa decimonónica.

La canción folclórica "Arroz con leche" cristaliza este mandato doméstico: "Arroz con leche / me quiero casar / con una señorita de San Nicolás / que sepa coser / que sepa bordar / que sepa abrir la puerta para ir a jugar". "Que sepa coser/ que sepa bordar" se superpone con la máquina de coser y los cursos de corte y confección, de los más difundidos durante las primeras décadas del siglo XX.

\section{Las preguntas por el barrio}

La fascinación y el rechazo que producen estas primeras décadas coagulan en un espacio que es el barrio. Escenarios urbanos que, ante la aceleración de los cambios, operan como extensión de la domesticidad para las mujeres. Las casas, construidas como espacios protegidos de los peligros urbanos, aparecen ampliadas hacia el barrio; como si las formas de vida hogareñas impregnasen esa configuración espacial. Así emerge la contraposición entre el barrio y otros espacios: el centro, el margen o incluso zonas dinamizantes, como la confitería o el tranvía. La arquitectura es producida a partir de esta superposición de cartografias, en las cuales los desplazamientos de las mujeres habilitan o delimitan zonas de orden familiar y recato; de trabajo y peligrosidad de la "caída"; de torsión, desafio o aventura ante estas dicotomías.

Los modos de leer estas configuraciones impactan en la subjetivación sobre las mujeres, que son quienes más afectan y son afectadas por estas transformaciones. La expresión "una mujer de su casa", como la intervención sobre aquellas subjetividades que cumplen las expectativas de la domesticidad -producción de valor doméstico, cuidado, pudor sexual-, se superpone con la expresión "una mujer de barrio", como aquella que permanece entre ciertas fronteras espaciales y no desafia las trayectorias de circulación establecidas. Estos desplazamientos y cruces producen prácticas de subjetivación, de modo que en una misma textualidad pueden alternar prácticas domésticas o barriales con otras que cuestionan la circulación establecida.

La operación de Borges sobre Carriego también puede leerse a partir de esta arquitectura de los espacios para las mujeres. Borges publica Evaristo Carriego en 1930. Más allá de lo que escriba sobre Carriego, la decisión táctica de tomarlo como objeto del texto recoloca esta operación 
sobre los espacios. Señala que "la mejor poesía de Carriego es la intitulada "Has vuelto"” (Borges, 2021, p. 413) -"de cuando era joven... / la novia... / ¡quién sabe!"-. Sobre "La costurerita que dio aquel mal paso", sugiere "su contratiempo orgánico-sentimental" (Borges, 2021, p. 403).

Ledesma (2019, p. 329) afirma que, lejos de documentar ese Palermo, Borges no propone cumplir una misión de cronista para la posteridad, sino autorizar el texto para dar ingreso a la literatura a un nuevo "Palermo de 1889", o para tomar ese Palermo en tanto apoyo para producir una nueva literatura. Esta intervención de recrudecimiento formal cristaliza en la elección de las fotografias "Paraguay al 2600" y "Palermo y Jean Jaurés, esquina Paraguay", de Horacio Coppola, incluidas en el libro. ${ }^{16}$ Esta operación enfatiza la apuesta formal por intervenir la afectación del barrio como espacio clave de disputa. Gorelik (2021, p. 81) lee que Coppola no "traduce" en imágenes a Borges, sino que hace emerger una forma arquitectónica y urbana novedosa porque, a diferencia de la vanguardia que rodea a Borges, es capaz de ver, con Borges y Le Corbusier, "una Buenos Aires diferente". Las imágenes muestran dos casas, dos fachadas, dos capturas que vehiculizan cierto silencio, casi un recogimiento frente a la velocidad de las mutaciones urbanas.

Las fotografias no ilustran, sino que articulan ese universo barrial; así se solidifica esta hipótesis: pensar a Carriego es pensar el barrio, y ese barrio en su domesticidad extendida es el espacio tanto de orden familiar como de frontera hacia otros desplazamientos que emprenden las mujeres. No son fotos de personas ni de acciones, ni siquiera de objetos. Son fotos de espacios. Estas fotografias tomadas en 1929 pueden pensarse en serie con los dibujos que Silvina Ocampo realiza tras la publicación de Borges de Luna de enfrente (1925) y son impresos en el número 42 de la revista Martín Fierro en 1927. En "Patio con luna" se observan los cimientos y la fachada de un patio con un cielo negro en el que sobresale la luna; en "El almacén rosado" la calle ocupa buena parte de la imagen. En ambos dibujos Silvina Ocampo enfatiza la estructura del patio y del almacén, casi al modo de croquis urbanos. Constelar los dibujos de Silvina Ocampo, que adelantan la imaginación de Coppola, permite mostrar que los espacios conforman arquitecturas porque ya tienen inscriptas las prácticas de subjetivación que las subjetividades de los 20 y de los 30 hicieron de ellos.

Treinta años después, una fotografia de Annemarie Heinrich in-

16. La exposición de fotografias que Grete Stern realiza junto a Coppola en 1935, a instancias de Sur, se considera fundacional de la fotografia moderna. Hasta entonces, la fotografia circula como una práctica familiar o comercial, pero esta exposición es releída como un "mito de origen" de esta recolocación artística del dispositivo fotográfico. Las series fotográficas de Stern y Coppola generan un dispositivo que fricciona los espacios y los modos de subjetivación. 
terviene las posibilidades de desplazamientos para las mujeres. ${ }^{17}$ En "Veraneando en la ciudad", el humo de la arquitectura puede ser visto desde una terraza donde una mujer posa en activo descanso. Esta fotografia lleva a una mujer al lugar más alto de la imaginación urbana -la azotea, casi tocando el cielo-, y así reescribe el ciclo de las costureritas y las imágenes precedentes sobre el barrio al poner el cuerpo de una mujer, que podría hipotetizarse como trabajadora, en el lugar máximo de un edificio. El "cielo por asalto", que se configura en los 70 como otra imaginación disponible, aparece contenido en esta icónica fotografia de Heinrich, que habilita en las mujeres una lógica espacial no circunscripta a la oposición entre centro y margen, o habilitado y prohibido, sino recolocada. Las costureritas van a llegar a la terraza.

\section{Reescribir el ciclo de las costureritas ${ }^{18}$}

El ciclo de las costureritas opera a través de la construcción del dispositivo de la costurerita sostenido entre la sociedad y la cultura, a partir de la lectura de la intersección de trabajos, sexos y géneros. Dentro de este prisma, las décadas del 20 y del 30 ofrecen apropiaciones, desvios, alianzas e interrogaciones sobre este ciclo en publicaciones de escritoras menos transitadas por la crítica como María Luisa Carnelli, Alicia Eguren, Nydia Lamarque, Salvadora Medina Onrubia y Amparo Mom, en las crónicas de Alfonsina Storni y Roberto Arlt, en la poesía de Nicolás Olivari, en la producción cinematográfica de Romero. ${ }^{19} \mathrm{El}$ cruce entre mujeres y trabajo encuentra dos antecedentes en los que la literalidad de "mujeres" y "trabajadoras" aparecen juntas: la columna que publica Storni en La Nación en 1920 "Las mujeres que trabajan" y la película de Romero de 1938 Mujeres que trabajan.

A partir de la lectura de estos materiales que superponen arte y sociedad, y politizan sus condiciones de enunciación e interpelación, se

17. Annemarie Heinrich (1912-2005) ilustra las tapas de las revistas Antena y Radiolandia, y en la década del 40 retrata a las estrellas del cine argentino. Es pionera de la fotografia artística.

18. Una versión previa de este apartado en torno a Carnelli ha sido publicada en Angilletta (2016).

19. Durante los años 20 y 30, Eguren (1925-1977), Lamarque (1906-1982), Medina Onrubia (1894-1972) y Mom (1896-1940), entre otras, escriben poesias, textos periodísticos y, en algunos casos, narraciones. Aun con sus diferencias, estas textualidades pueden ponerse en serie porque participan de la reescritura del ciclo de las costureritas al reimaginar otras prácticas de subjetividad para las mujeres sobre el trabajo (Medina Onrubia), la moda (Mom en Contra) y el lenguaje (Eguren, Lamarque), a partir de una modulación que combina su militancia de izquierda con sus condiciones de enunciación sexo-genéricas. 
tensionan las preguntas en torno a los cruces sobre género y clase, así como también acerca de los accesos diferenciales, las alianzas inesperadas y los devenires minoritarios ante las vertiginosas transformaciones de la primera mitad del siglo XX. Leer a partir de los feminismos no implica agotar en esa lectura el impacto de sus significaciones sino, más bien, producir contactos novedosos entre series que permitan otra lectura sobre esas décadas en su conjunto.

El ciclo de las costureritas es parte de la ciudad urbana porque resulta indisociable de la cartografia que funda el barrio como una extensión de la domesticidad, frente al centro, escenario de transgresiones y excesos, y distinto de otras configuraciones espaciales. La urbanización acontece en lo que sucede en la suma de estas arquitecturas: barrial, central, marginal. Las relaciones de las mujeres con estas cartografias son conflictivas, en parte porque las trayectorias urbanas son tan deseadas como rechazadas. La tensión entre circulación y virtud extrema el riesgo de que las mujeres "públicas" -en tanto se desplazan del ámbito privado- sean prostituibles.

Carnelli publica la novela iQuiero trabajo! (1933), veinte años después de "La costurerita que dio aquel mal paso". ${ }^{20}$ En iQuiero trabajo! puede leerse la acelerada transformación del mundo laboral, de la urbanización y de las formas de vida para varones y mujeres. ${ }^{21}$ Los efectos de este cambio se avizoran en la novela desde el comienzo con la mención de los postigos y el ingreso de la luz a la casa, como el espacio social que ya es parte de la intimidad, el contacto entre lo público y lo privado y la difusión de esas fronteras: "Desde afuera llegan [...] un olor confuso de frituras, de humo y de óxido de carbón” (Carnelli, 1933, p. 25). ¡Quiero trabajo! insiste en la serie de esos espacios u objetos fronterizos -la puerta, la ventana, el transporte- que tramitan la circulación entre el afuera y el adentro, lo privado y lo público, lo íntimo y lo social, y emergen como

20. Afin a las politicas de izquierda, Carnelli (1898-1987) milita en el Partido Comunista y viaja como corresponsal de la revista Ahora a España, donde mantiene una activa participación en el frente republicano durante la Guerra civil. Entre los años 20 y 30, publica artículos en revistas como Noticias Gráficas, El Hogar, Caras y Caretas y Atlántida; los poemarios en un principio ligados a la retórica de la intimidad-Versos de una mujer (1923), Rama frágil (1925)- y luego a la denuncia social -Poemas para la ventana del pobre (1928), Mariposas venidas del horizonte (1929)-; junto a su única novela, iQuiero trabajo! (1933).

21. ¡Quiero trabajo! se estructura en tres partes. En la primera, se relata la infancia de Susana Miller, su protagonista, y el fin de su adolescencia, con la iniciación sexual y el casamiento. La segunda parte comienza con un aborto y continúa con su matrimonio atravesado por la pobreza, su partida de la casa y el inicio en la prostitución, a lo que continúa un nuevo intento amoroso en el que vuelve a fracasar. La tercera parte está compuesta por escenas de explotación entre patrones y empleados, y la insistente búsqueda de trabajo que culmina con un llamamiento revolucionario. 
zonas de la reinvención de lo común. Para ser afectados, ni las casas ni los modos de subjetivación están exentos de esas transformaciones: son un perfume que llega hasta la nariz.

La madre de Susana es construida como costurera: "La madre cose en la Singer dale que dale. El ruido del pedal, monótono, amodorrante, acompaña su romántica canción" (p. 25). Así, es "costurera" pero no "costurerita"; los modos de subjetivación de la madre se vinculan con los de las mujeres domésticas, frente a los cuales se oponen los modos de subjetivación de Susana. En efecto, tras el fin de su matrimonio, la protagonista se pregunta “ ¿hacia dónde encaminar los pasos?", y luego, tras otro traspié amoroso, "¿ ¿adónde ir otra vez que no tropiece siempre con los pedazos de mi rota esperanza?” (pp. 58, 78). Si ya no es posible el espacio del hogar paterno ni del hogar matrimonial, ¿qué otro espacio podria llegar a habilitarse para las mujeres?

Estas preguntas -en apariencia retóricas- muestran la ficción política del "mal paso" como una producción que opone modos de subjetivación -esposa/prostituta- y espacios -hogar/prostíbulo-. Los flujos entre modos de subjetivación y espacios son tan próximos que la "caída" se textualiza con una imagen de movimiento: "dar el mal paso". Esta operación se complementa con el procedimiento de la elipsis que media entre la pregunta y el párrafo siguiente en el que Susana ya ha devenido prostituta: "Este baño tibio [...], esta mesa provista, este interior suntuoso, estos billetes nuevecitos que se renuevan siempre en mi cartera" (p. 61). La elipsis refuerza la operatividad de la ficción política del "mal paso" en tanto es la época la que arma una causalidad entre el final matrimonial y la prostitución. ${ }^{22}$

La narración, que alterna entre la tercera y la primera persona, en la tercera parte muta hacia una diseminación del "yo", mediante la superposición de distintos fragmentos que funcionan al modo de un collage roto sobre el trabajo femenino. Así aumenta desde la textualización el volumen social de la trayectoria singular de cada trabajadora. La historia de Susana es la de una época. A través de esta torsión, el texto esboza modos de poner en jaque lo común. El efecto se construye por la yuxtaposición de distintos fragmentos que denuncian las condiciones de trabajadores y trabajadoras.

Sarlo (1988, p. 129) analiza el modo en que la Revolución rusa les brinda, a quienes no tienen la legitimación de la alfabetización tradicional, el acceso a una "nueva cultura politica". Así, iQuiero trabajo! tramita esos "saberes" a los que se refiere Sarlo, a la vez que produce una torsión respecto del ciclo de las costureritas: genera en la textualidad 
misma la inclusión de estas intelectuales dentro de esta nueva cultura política. La izquierda es la manera en que se organiza esta errancia y el contacto con lo laboral como un modo de constitución de estas formas de vida. La revolución resulta legible en un movimiento doble: permite mostrar formas de organización social y, a la vez, habilita la reconfiguración de las relaciones de género y la promoción de la unión "feminista": "Mujeres de toda la tierra, hombro con hombro, trencemos la cadena, solidariamente" (Carnelli, 1933, p. 101).

La textualidad de iQuiero trabajo! enlaza una forma de articular los modos de subjetivación con las multitudes, que también organiza a la película Mujeres que trabajan, de Romero. ${ }^{23} \mathrm{El}$ foco del film no es solo mostrar a las mujeres trabajadoras, sino leerlas en el espacio de la multitud, tanto en la pensión como en la tienda donde trabajan y, en especial en la escena final, al abandonar sus puestos. La reescritura del ciclo de las costureritas aparece en la historia de Clara, la secretaria del dueño de la tienda, con quien mantiene un romance. Cuando queda embarazada, él se desentiende. Si bien ante el embarazo se reactivan nudos melodramáticos (Clara no sabe cómo explicárselo a sus padres que viven lejos), sobresale la dinamización de lo común que propulsa esta "caída". ${ }^{24}$ En la pensión las compañeras dicen "nosotras lo criaremos, será nuestro hijo" y ninguna de las trabajadoras moraliza el desenlace ni le pregunta por qué tuvo relaciones sexuales antes del matrimonio.

El final de la película está organizado por la huelga en la tienda y el abandono de los puestos de trabajo. El motivo que impulsa esta decisión

23. Romero (1891-1954) compone letras de tango, piezas teatrales y es un prolífico cineasta. Los años del apogeo de su producción coinciden con la denominada "edad de oro" del cine argentino. Su filmografia está atravesada por el problema del trabajo para las mujeres. La película seleccionada, de 1938, resulta inaugural como torsión del ciclo de las costureritas y constituye el debut cinematográfico de Niní Marshall en el personaje de Catita. El film se articula a partir de la trama "niña bien en desgracia": la protagonista vive de juerga, pero su vida cambia ante el suicidio de su padre por dificultades económicas. El chofer de su casa opera como una mediación entre mundos (ocio/trabajo) y la lleva a vivir a una pensión con trabajadoras. En esta estadía -como ellas-, empieza a trabajar como vendedora de tienda, mientras se distancia de la relación con su histórico pretendiente. Mantiene un fugaz romance con el dueño de la tienda, hasta que se entera de que otra trabajadora ha quedado embarazada de él. La trama conjuga la historia de la protagonista y el derrotero de "la costurerita", en torno al "mal paso", con las de las trabajadoras que viven en la pensión (Catita, la comunista, entre otras). Hacia el final, más allá de los desenlaces particulares, lo que se enfatiza es la puesta en común de sus formas de vida como modos de producir una afectación entre ellas que desborda las singularidades hacia la multitud.

24. Sobre melodrama, ver Karush (2013); acerca de la vinculación del "mal paso" con la Argentina peronista, ver Acha (2013). 
es afectivo, pero aún así se esboza la posibilidad de constituirse como multitud ante una escena laboral. El matrimonio aparece como un horizonte de regulaciones genéricas (la trabajadora "comunista" dice "tal vez si hubiera encontrado el amor no leería tanto"), aunque la afectación como trabajadora no puede ser escindida de este tándem. De hecho, la protagonista señala que ya no puede volver a la vida ( $\sin$ trabajo) de antes, porque "es una mujer que trabaja", a lo que el partenaire responde que él también "será un hombre que trabaja".

Así, aunque persistan núcleos de sujeción, no se aligeran las contradicciones que el film motoriza al propulsar una reescritura del ciclo de las costureritas vinculada a un espacio social distinto (la pensión y la tienda), y a una reinvención de lo común puesta en marcha por el encuentro entre las mujeres (con origenes de clase distintos). En todas estas lateralizaciones el trabajo es leído como una afectación central de los modos de vida, no meramente una necesidad ligada a condiciones materiales, sino productor de una educación sentimental específica, imposible ya de reducir a una mera pedagogía o moral aplanadora ("pobre pero honrada"), al incorporar afectos diversos, como la astucia y la incertidumbre.

En el film el embarazo es el peligro máximo de "dar el mal paso". Pero la torsión es la incorporación de la multitud como modo de tramitación frente a esta narrativa de los 20 y los 30 . La ficción política reinventa la común, y es esta matriz la que años después fricciona la productividad del peronismo, así como su desborde: la multitud y lo común en tanto aquello que propulsa y a la vez aquello que nunca puede ser obturado o contenido por completo. En el ciclo de las costureritas se diferencia lo común de la comunidad. La comunidad es la coagulación, estabilización o cristalización de esa triangulación entre lo instituyente y lo instituido que es lo común, un viaje que no se detiene.

\section{Costureritas: travesías entre siglos}

Tanto los modos de vivir -y producir narrativas sobre las vidascomo las formas de la política atraviesan y son atravesadas por los feminismos. La operación es doble: la política está intersectada por los sexos y géneros, a la vez que la sexualidad es una producción política. Pero si todo es, nada es: las ficciones crujen y hacen crujir acuerdos y desacuerdos. Rancière (1996, p. 48) puntúa la diferencia entre poder y política, y cuestiona a quienes buscan "asegurar que "todo es político" porque en todos lados hay relaciones de poder". Más que del desborde de la política sobre la economía o la sociedad -la producción de la vida-, se intenta leer las conquistas de lo común que los órdenes textuales y 
sexuales producen de un modo inaugural en esas décadas y que aún atraviesan el presente.

Las lecturas "desde el género" (Molloy, 2002) funcionan como llaves, no para guetificar análisis que solo "lean" con exhaustividad las problemáticas de mujeres y las disidencias sexuales, sino para construir aperturas que propulsen nuevos acercamientos a las dinámicas de género, así como también otras sobre el conjunto de la época. En definitiva, esta operación crítica permite, más que nombrar aportes novedosos sobre la historia de las mujeres, discutir la época misma, sus articulaciones, sus efectos (Arnés, 2016; Domínguez, 2007; Masiello, 1997; entre otras).

Las vinculaciones entre historia, politica y feminismos no se piensan al modo de un aplicacionismo -leer cómo un período se "representa" en la literatura-, sino que la literatura es productora de época. Tampoco se trata de encontrar correspondencias entre la serie histórica y la literaria, o de proponer dos series paralelas. Más bien se trata de poner en interdicción la misma noción de serie literaria/histórica, y leer la capilaridad y multiplicidad con que un conjunto de materiales, entre los que se encuentra la literatura, producen una época.

La literatura argentina fabrica regímenes de sensibilidad que muestran estas zonas comunes, sus aventuras, sus riesgos. Los feminismos ensayan, al menos, dos operaciones. Sacuden los archivos para poner de manifiesto las negociaciones, tensiones e intervenciones que las mujeres y las disidencias sexuales hacen con lo que el trabajo hace de ellas. Y también vuelven sobre las historias mínimas, fugaces, silvestres, quienes dan "pequeños grandes saltos" con sus condiciones de posibilidad. Lo común se configura entre ambas zonas: entre las historias de grandes saltos en lo público y esos pequeños pasos, historias minimas.

La productividad del ciclo de las costureritas entre los años 20 y 30 culmina en "las muchachas de antes" que escriben, como Eva Perón en cierta forma la "última costurerita", quien es así nombrada, aunque nunca cose un ojal- o como "las patas en la fuente" de Tita Merello al entonar "Se dice de mí", en tanto reescritura de la respetabilidad. A la vez, continúa en la historia de Celia Alcántara -ícono de la telenovela, costurera que triunfa como diseñadora de modas-, en los cuadros de Daniel Santoro, en la lucha obrera de Brukman, en cualquier conversación o periódico en que se siga discutiendo dónde está el trabajo.

\section{Referencias}

AA.VV. (1999). La Novela Semanal (1917-1926). Universidad Nacional de Quilmes-Página/12.

Acha, O. (2013). Crónica sentimental de la argentina peronista. Sexo, inconsciente e ideología, 1945-1955. Prometeo. 
Alle, M.F. (2015). Literatura, cultura y pensamiento de izquierdas en la Argentina del siglo XX. Badebec, 5 (09), pp. 180-197.

Angilletta, F. (2016). ¡Quiero trabajo!, de María Luisa Carnelli: subjetividad feminista revolucionaria en la Buenos Aires de 1930. Badebec, 6 (11), pp. 374-392.

Armstrong, N. (1987). Deseo y ficción doméstica: Una historia politica de la novela. Cátedra.

Armus, D. (2002). El viaje al centro: Tísicas, costureritas y milonguitas en Buenos Aires (1910-1940). En D. Armus (ed.), Entre médicos y curanderos: Cultura, historia y enfermedad en América Latina moderna. Norma.

Arnés, L. (2016). Ficciones lesbianas. Madreselva.

Barrancos, D. (1999). "Moral sexual, sexualidad y mujeres trabajadoras en el período de entreguerras”. En F. Devoto y M. Madero (dirs.), Historia de la vida privada en Argentina: La Argentina entre multitudes y soledades. Taurus.

Beter, C. [C. Tiempo] (1926). Versos de una... Claridad.

Borges, J.L. (2021). Evaristo Carriego [1930]. En Obras completas, I. Sudamericana.

Carnelli, M.L. (1933). iQuiero trabajo! Tor.

Carriego, E. (1999). Obra completa. Corregidor.

Despentes, V. (2007). Teoria King Kong. Melusina.

Diz, T. (2010). Subjetividades sexuadas en las glosas de Enrique González Tuñón. Revista cientifica de UCES, 14 (1), pp. 56-65.

Diz, T. (2012). Imaginación falogocéntrica y feminista, diferencia sexual y escritura en Roberto Arlt, Alfonsina Storni, Enrique González Tuñón, Roberto Mariani, Nicolás Olivari, Salvadora Medina Onrubia y María Luisa Carnelli. FLACSO.

Domínguez, N. (2007). De dónde vienen los niños: Maternidad y escritura en la cultura argentina. Beatriz Viterbo.

Freidemberg, D. (1996). Estudio preliminar. En E. Carriego, Poesias completas. Losada.

González Tuñón, E. (2003). Tangos [1926]. Librería Histórica.

Gorelik, A. (2021). Horacio Coppola, 1929. Borges, Le Corbusier y las casitas de Buenos Aires. En N. Brizuela y A. Uslenghi (comps.), La cámara como método. La fotografía moderna de Grete Stern y Horacio Coppola. Eterna Cadencia.

Habermas, J. (1981). Historia y crítica de la opinión pública. Gustavo Gili.

Karush, M. (2013). Cultura de clase. Radio y cine en la creación de una Argentina dividida (1920-1946). Ariel.

Ledesma, J. (2019). X y Z. La literatura entre De Quincey y Borges. FFyL-UBA.

Lobato, M. (2007). Historia de las trabajadoras en la Argentina (1869-1960). Edhasa.

Ludmer, J. (1985). Las tretas del débil. En P. González y E. González, La sartén por el mango. Huracán. 
Malosetti Costa, L. (2001). Los primeros modernos. Arte y sociedad en Buenos Aires a fines del siglo XIX. Fondo de Cultura Económica .

Masiello, F. (1997). Entre civilización y barbarie. Mujeres, nación y cultura literaria en la Argentina moderna. Beatriz Viterbo.

Mitidieri, G. (2021). Costureras, modistas, sastres y aprendices. Una aproximación al mundo del trabajo de la aguja. Buenos Aires, 1852-1862. Editorial de la Universidad Nacional de Mar del Plata.

Molloy, S. (2002). La flexión del género en el texto cultural latinoamericano. Cuadernos de Literatura, 8 (15), pp. 161-167.

Monteleone, J. (2006). La invención de la ciudad. En A. Rubione, La crisis de las formas. Emecé.

Nari, M. (2004). Politicas de maternidad y maternalismo politico: Buenos Aires 1890-1940. Biblos.

Olivari, N. (2008). Poesías 1920-1930 [1924]. E1 8vo Loco.

Preciado, P.B. (2010). Pornotopía: arquitectura y sexualidad en Playboy durante la guerra fría. Anagrama.

Queirolo, G. (2020). Mujeres que trabajan. Labores femeninas, Estado y sindicatos (Buenos Aires, 1910-1960). Editorial de la Universidad Nacional de Mar del Plata.

Rancière, J. (1996). El desacuerdo: politica y filosofía. Nueva Visión.

Romano, E. (2007). Las letras del tango: Antología cronológica 1900-1980. Fundación Ross.

Saitta, S. (2006). "Costureritas y artistas pobres: algunas variaciones sobre el mito romántico de la tuberculosis en la literatura argentina”. En W. Bongers y T. Olbrich (comps.), Literatura, cultura, enfermedad. Paidós.

Salomone, A. (2006). Alfonsina Storni: Mujeres, modernidad y literatura. Corregidor.

Sarlo, B. (1988). Una modernidad periférica. Nueva Visión.

Saulquin, S. (2006). Historia de la moda argentina. Emecé.

Scott, J. (1993). La mujer trabajadora en el siglo XIX. En G. Duby y M. Perrot (dirs.), Historia de las mujeres en Occidente. El siglo XIX. Taurus.

Tossounian, C. (2021). La joven moderna en la Argentina de entreguerras. Género, nación y cultura popular. Prohistoria.

Varela, G. (2016). Tango y politica. Sexo, moral burguesa y revolución en la Argentina. Ariel.

Vitagliano, M. (comp.) (2012). Boedo: Politicas del realismo. Editorial Título. 